\title{
A cross-sectional survey of current treatment and symptom burden of patients with COPD consulting for routine care according to GOLD 2014 classifications
}

\author{
This article was published in the following Dove Press journal: \\ International journal of COPD \\ 23 May 2017 \\ Number of times this article has been viewed
}

\section{Bo Ding' \\ Mark Small ${ }^{2}$ \\ Ulf Holmgren ${ }^{3}$}

'Medical Evidence and Observational Research, AstraZeneca Gothenburg, Mölndal, Sweden; ${ }^{2}$ Real World

Research (Respiratory), Adelphi Real World, Bollington, UK; ${ }^{3}$ Global Payer Evidence and Pricing, AstraZeneca Gothenburg, Mölndal, Sweden
Correspondence: Bo Ding Medical Evidence and Observational Research, Global Medical Affairs, AstraZeneca Gothenburg, Pepparedsleden I, SE-43I 83 Mölndal, Sweden

Tel +46 3I 7762406

Email bo.ding@astrazeneca.com
Background: As part of the Respiratory Disease Specific Program (DSP) conducted to provide observations of clinical practice from a physician and matched patient viewpoint, this study aimed to establish how patients with COPD are treated according to the Global Initiative for Chronic Obstructive Lung Disease (GOLD) classification system and to quantify the symptom burden.

Methods: Data were obtained from the Respiratory DSP, a cross-sectional survey of patients with a diagnosis of COPD consulting for routine care in France, Germany, Italy, Spain, the UK, and the USA during the third quarter of 2013. Patients' exacerbation risk and symptom data were used for classification into GOLD groups A-D based on GOLD 2014 criteria. Prescribing practices were stratified by physician type and time since patient diagnosis.

Results: A total of 903 physicians participated in the Respiratory DSP, with data from 1,641 patients included in this analysis. Most patients were classified into GOLD groups B ( $\mathrm{n}=742$; $45.2 \%)$ and D ( $=704 ; 42.9 \%)$. Patients in groups A and D were most likely to be treated in line with GOLD recommendations (61.5\% and $77.5 \%$, respectively), compared with $40.1 \%$ for group B. Patients with a diagnosis within the past 12 months were more likely to be treated according to recommendations. Inhaled corticosteroids (ICSs) in combination with one or more long-acting bronchodilator were prescribed across all GOLD groups. Patterns of treatment were, in general, similar for patients treated by a primary care physician or a pulmonologist. COPD assessment test scores $\geq 10$ indicating a high symptom burden were reported for $>80 \%$ of patients.

Conclusion: This analysis confirmed a high symptom burden among patients with COPD and indicates some misalignment of prescribing with GOLD recommendations, particularly regarding the role of ICS/long-acting $\beta_{2}$-agonist (LABA) and ICS/LABA + long-acting muscarinic antagonist combinations across the different GOLD groups.

Keywords: bronchodilators, COPD, treatment, GOLD group, symptom, routine care

\section{Introduction}

Many patients with COPD are not able to achieve optimal control of COPD symptoms, despite the availability of several types of bronchodilator and anti-inflammatory therapies. ${ }^{1}$ Relieving patients' current symptoms in order to reduce the impact on their daily activities, as well as lowering the risk of future exacerbations and preventing disease progression, are key goals of the management of stable COPD. ${ }^{2}$

Patients with COPD experience several different symptoms, including dyspnea, wheezing, and chest tightness, which can vary across 24 hours. ${ }^{1,3,4}$ Increased prevalence 
of dyspnea has been associated with elevated risk of a COPD exacerbation ${ }^{5}$ and mortality. ${ }^{6}$ COPD symptoms leading to sleep disturbance have also been associated with an increased risk of exacerbations. ${ }^{7,8}$ The evaluation of symptoms has, therefore, become an important part of COPD assessment in order to inform treatment decisions. ${ }^{2,9}$

Spirometric assessment of airflow limitation is essential for a correct diagnosis of COPD; ${ }^{2,10}$ however, airflow limitation does not necessarily correlate with symptoms and other patient-reported outcomes. ${ }^{11}$ The 2011 update of the Global Initiative for Chronic Obstructive Lung Disease (GOLD) strategy introduced a new classification system that classifies patients into one of four GOLD groups (A-D) based on exacerbation risk (low/high from analysis of history of exacerbations in the previous 12 months) and symptoms (more/less), in addition to forced expiratory volume in 1 second $\left(\mathrm{FEV}_{1}\right)$. However, there is evidence that prescribing of treatment for COPD is not in line with GOLD recommendations, ${ }^{12,13}$ and patients with COPD are still not receiving the appropriate maintenance treatment to optimize the management of their condition. ${ }^{13-16}$

This study was part of a program conducted to provide impartial observations of real-world clinical practice from a physician and matched patient viewpoint. The aim of the study was to establish how patients with COPD are being treated according to the GOLD 2014 strategy and to quantify the proportion of patients with a symptom burden, indicating that they are likely to require a treatment review.

\section{Methods}

\section{Study design}

Data were obtained from the Respiratory Disease Specific Program (DSP; administered by Adelphi Real World, Bollington, UK), a cross-sectional survey conducted to provide impartial observations of real-world clinical practice from a physician and matched patient viewpoint. ${ }^{17}$ The Respiratory DSP collected information from patients diagnosed with COPD consulting for routine care in France, Germany, Italy, Spain, the UK, and the USA during the third quarter of 2013. The research was conducted as a market research survey adhering to the International Chamber of Commerce/European Society for Opinion and Marketing Research (ICC/ESOMAR) international code on observational research and performed in full accordance with the rules of the US Health Insurance Portability and Accountability Act 1996. Therefore, ethics approval was not necessary to obtain and was not sought. All data were anonymized and aggregated prior to receipt by Adelphi Real World. The Respiratory DSP was not conducted to test any specific hypothesis.

\section{Study populations \\ Physicians}

Physicians who became medically qualified between 5 and 35 years ago and were responsible for the treatment of patients with COPD were eligible to participate in the Respiratory DSP. Eligible physicians had to evaluate $\geq 3$ patients per month in order to ensure study completion on time, and they were asked to complete the survey for five consecutive patients.

\section{Patients}

Patients $>40$ years of age with confirmed airflow obstruction and a diagnosis of COPD (including emphysema and chronic bronchitis) were only eligible for the Respiratory DSP survey. Also, the patients were required to have their exacerbation frequency recorded or their most recent post-bronchodilator $\mathrm{FEV}_{1} \%$ predicted in the previous 12 months and to have completed a full COPD assessment test $(\mathrm{CAT})^{18}$ questionnaire in order to define current GOLD classification. Patients with a concomitant diagnosis of asthma were excluded.

\section{Variables and measurements}

Population-descriptive variables (demographics, smoking history, employment status, education, comorbidities, medical insurance, physician type, $\mathrm{FEV}_{1} \%$ predicted, and number of exacerbations in the previous 12 months), symptoms (CAT scores), current treatment, GOLD classification variables (number of exacerbations in the previous 12 months, exacerbation treatment, $\mathrm{FEV}_{1} \%$ predicted, $\mathrm{FEV}_{1}$ test undertaken in the previous 12 months, CAT score), physicianand patient-reported level of control of COPD, duration of diagnosis, and subjective GOLD group (physician-reported via tick box) were recorded. Exacerbations were defined as worsening of symptoms beyond normal day-to-day variation requiring oral corticosteroids, antibiotics, or both, or emergency room (ER) treatment or hospitalization.

The objective GOLD group classification was calculated by the treating physician based on each patient's risk and symptom data. ${ }^{10}$ The GOLD groups were defined as: A, exacerbation frequency $\left(\mathrm{Ex}_{\mathrm{n}}\right)<2$ per year and no ER visits or hospitalization, $\mathrm{FEV}_{1} \geq 50 \%$ predicted, CAT score $<10$; $\mathrm{B}, \mathrm{Ex}_{\mathrm{n}}<2$ and no ER visits or hospitalization, $\mathrm{FEV}_{1} \geq 50 \%$, CAT score $\geq 10 ; C, E x_{n} \geq 2$ or one $E R$ visit or hospitalization, $\mathrm{FEV}_{1}<50 \%$, CAT score $<10$; and D, $\mathrm{Ex}_{\mathrm{n}} \geq 2$ or one $\mathrm{ER}$ visit or hospitalization, $\mathrm{FEV}_{1}<50 \%$, CAT score $\geq 10$.

\section{Outcomes}

For each GOLD group, the proportion of patients currently prescribed each of the main therapy classes was recorded for each physician type responsible for treatment. The same 
analysis was performed for patients diagnosed and started on treatment $\leq 12$ months prior to data collection, to allow comparison of newly diagnosed patients with those with a longer duration of diagnosis.

The proportion of patients with a symptom burden was quantified according to CAT mean and domain scores.

\section{Statistical analyses}

Fisher's exact tests were performed to test for significant differences in prescribed treatment between the imposed GOLD groups A-D. No imputation was used for missing values. The proportions of patients meeting CAT symptom threshold criteria and mean scores with 95\% confidence intervals were stratified by treatment.

\section{Results}

\section{Study population}

A total of 903 primary care physicians and pulmonologists participated in the Respiratory DSP (France: $n=140$; Germany: $n=162$; Italy: $n=140$; Spain: $n=140$; UK: $n=111$; USA: $n=210$ ). During the observation period (quarter 4, 2013), data were recorded for a total of 3,843 patients with COPD. Of these, 1,641 patients (France: $n=277$; Germany: $\mathrm{n}=363$; Italy: $\mathrm{n}=162$; Spain: $\mathrm{n}=318$; UK: $\mathrm{n}=115$; USA: $\mathrm{n}=406$ ) agreed to participate in the survey and were eligible for inclusion in the study population. Patient refusal to participate in the survey was the main reason for ineligibility.

Most of the patients were classified as GOLD group B ( $n=742 ; 45.2 \%$ overall) or $\mathrm{D}(\mathrm{n}=704 ; 42.9 \%$ overall $)$, both of which are associated with a high symptom burden (Figure 1).
Only 26 patients (1.6\%) were classified as GOLD group C. The GOLD group distribution was, in general, similar across countries.

Patient characteristics by GOLD group are shown in Table 1. Overall, the average age was 65.8 years. Patients in group D had the highest mean age consistent with later stage COPD and a more comorbid profile. The majority of patients were male $(68.1 \%)$ and $>90 \%$ of patients were Caucasian. Approximately $50 \%$ of patients were receiving specialist care, which increased to $60 \%$ for patients in group D. Overall, 20.6\% of patients had been diagnosed within $\leq 12$ months of participating in the survey, with the lowest proportions of recently diagnosed patients in groups C and D (9.1\% and 12.8\%, respectively). In group B, 29.8\% of patients had experienced one exacerbation in the previous 12 months, compared with $12.6 \%$ for group A.

Overall, $41.2 \%$ of patients reported CAT scores of 20-29, approximately a third (31.7\%) had CAT scores of $10-19,15.2 \%$ had CAT scores of $30-40$, and $11.9 \%$ had CAT scores of $0-9$.

\section{Treatment by GOLD group}

\section{Current treatment according to objective GOLD} classification

The majority of patients in GOLD groups A and D were currently being prescribed treatments recommended by GOLD $(61.5 \%$ and $77.4 \%$, respectively $),{ }^{10}$ whereas in groups B and $\mathrm{C}, \leq 40 \%$ of patients were prescribed therapies recommended by GOLD ${ }^{10}$ (Table 2).

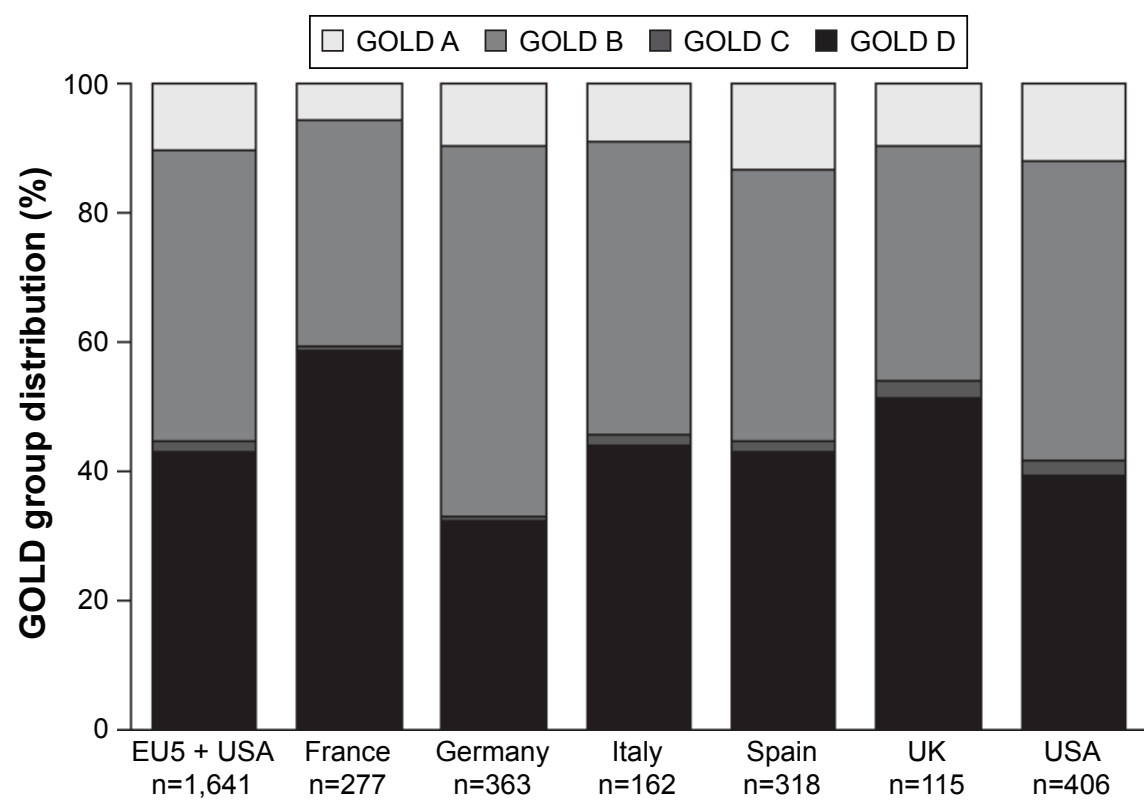

Figure I GOLD group distribution by country according to objective GOLD classification.

Abbreviations: EU5, France, Germany, Italy, Spain, and UK; GOLD, Global Initiative for Chronic Obstructive Lung Disease. 
Table I Patient characteristics according to objective GOLD classification

\begin{tabular}{|c|c|c|c|c|c|}
\hline Characteristic & $\begin{array}{l}\text { Overall } \\
n=I, 64 I\end{array}$ & $\begin{array}{l}\text { Group A } \\
n=169\end{array}$ & $\begin{array}{l}\text { Group B } \\
n=742\end{array}$ & $\begin{array}{l}\text { Group C } \\
n=26\end{array}$ & $\begin{array}{l}\text { Group D } \\
n=704\end{array}$ \\
\hline \multicolumn{6}{|l|}{ Age (years) } \\
\hline Mean (SD) & $65.8(10.3)$ & $62.6(10.1)$ & $65(10.2)$ & $61.6(11.4)$ & $67.6(10.1)$ \\
\hline Range & $40.0-90.0$ & $42.0-86.0$ & $41.0-90.0$ & $43.0-79.0$ & $40.0-90.0$ \\
\hline \multicolumn{6}{|l|}{ Gender } \\
\hline Male, n (\%) & $\mathrm{I}, \mathrm{I} \mid \mathrm{8}(68 . \mathrm{I})$ & $112(66.3)$ & $510(68.7)$ & $16(61.5)$ & $480(68.2)$ \\
\hline Smoking status & $\mathrm{n}=\mathrm{I}, 638$ & $\mathrm{n}=168$ & $\mathrm{n}=742$ & $\mathrm{n}=26$ & $\mathrm{n}=702$ \\
\hline Current smoker (\%) & $54 I(33.0)$ & $58(34.5)$ & $246(33.2)$ & $10(38.5)$ & $227(32.3)$ \\
\hline Ex-smoker (\%) & $1010(61.7)$ & $98(58.3)$ & $450(60.6)$ & I 4 (53.8) & $448(63.8)$ \\
\hline Never smoked (\%) & $87(5.3)$ & $12(7.1)$ & $46(6.2)$ & $2(7.7)$ & $27(3.8)$ \\
\hline Physician responsible for treatment decisions & $n=1,630$ & $\mathrm{n}=168$ & $\mathrm{n}=739$ & $\mathrm{n}=26$ & $\mathrm{n}=697$ \\
\hline Primary care physician only, $\mathrm{n}(\%)$ & $704(43.2)$ & $84(50.0)$ & $333(45.1)$ & $12(46.2)$ & $275(39.5)$ \\
\hline Pulmonologist, n (\%) & $926(56.8)$ & $84(50.0)$ & $406(54.9)$ & $14(53.8)$ & $422(60.5)$ \\
\hline Most recent $\mathrm{FEV}_{1} \%$ predicted (post-bronchodilator) & $\mathrm{n}=745$ & $\mathrm{n}=76$ & $\mathrm{n}=303$ & $\mathrm{n}=14$ & $\mathrm{n}=352$ \\
\hline Mean (SD) & $63.7(17.9)$ & $74(12.2)$ & $72.4(13.1)$ & $55.6(20.8)$ & $54.2(17.4)$ \\
\hline $95 \% \mathrm{Cl}$ & $62.4,64.9$ & $71.2,76.8$ & $70.9,73.9$ & $43.6,67.7$ & $52.4,56.1$ \\
\hline CAT score & $n=|, 64|$ & $n=169$ & $\mathrm{n}=742$ & $n=26$ & $\mathrm{n}=704$ \\
\hline Mean (SD) & $20.4(8.4)$ & $5.9(2.4)$ & $19.7(6.0)$ & $7.3(2.2)$ & $25.1(6.8)$ \\
\hline Exacerbations within previous 12 months $^{\mathrm{a}}$ & $\mathrm{n}=1,625$ & $n=167$ & $n=731$ & $n=26$ & $\mathrm{n}=70 \mathrm{I}$ \\
\hline 0 & $724(44.6)$ & $146(87.4)$ & $513(70.2)$ & $3(11.5)$ & $62(8.8)$ \\
\hline 1 & $320(19.7)$ & $21(12.6)$ & $218(29.8)$ & $4(15.4)$ & $77(11.0)$ \\
\hline 2 & $283(17.4)$ & 0 & 0 & $15(57.7)$ & $268(38.2)$ \\
\hline$\geq 3$ & $298(18.3)$ & 0 & 0 & $4(15.4)$ & $294(41.9)$ \\
\hline Time since diagnosis (12-month split) & $n=1,391$ & $\mathrm{n}=148$ & $\mathrm{n}=635$ & $\mathrm{n}=22$ & $\mathrm{n}=586$ \\
\hline$\leq 12$ months, $\mathrm{n}(\%)$ & $287(20.6)$ & $60(40.5)$ & $150(23.6)$ & $2(9.1)$ & $75(12.8)$ \\
\hline$>12$ months, $n(\%)$ & I, $104(79.4)$ & $88(59.5)$ & $485(76.4)$ & $20(90.9)$ & $5 I I(87.2)$ \\
\hline
\end{tabular}

Note: ${ }^{a}$ Exacerbations treated with oral corticosteroids, antibiotics, or both, or requiring emergency-room visits or hospitalization.

Abbreviations: CAT, COPD assessment test; $\mathrm{Cl}$, confidence interval; FEV , forced expiratory volume in I second; GOLD, Global Initiative for Chronic Obstructive Lung Disease; SD, standard deviation.

Table 2 Current treatment by objective GOLD group classification ${ }^{\mathrm{a}}$

\begin{tabular}{|c|c|c|c|c|c|}
\hline Patients, n (\%) & $\begin{array}{l}\text { Group A } \\
n=169\end{array}$ & $\begin{array}{l}\text { Group B } \\
\mathrm{n}=742\end{array}$ & $\begin{array}{l}\text { Group C } \\
n=26\end{array}$ & $\begin{array}{l}\text { Group D } \\
n=704\end{array}$ & $P$-value \\
\hline Short-acting only & $32(18.9)$ & $66(8.9)$ & 0 & $10(1.4)$ & $<0.001$ \\
\hline LABA & $15(8.9)$ & $39(5.3)$ & I (3.8) & $24(3.4)$ & 0.024 \\
\hline LAMA & $57(33.7)$ & $198(26.7)$ & $2(7.7)$ & $52(7.4)$ & $<0.001$ \\
\hline ICS/LABA & $26(15.4)$ & $154(20.8)$ & $5(19.2)$ & $125(17.8)$ & 0.304 \\
\hline ICS + LABA & I (0.6) & $4(0.5)$ & 0 & II (I.6) & 0.213 \\
\hline ICS + LAMA & I $(0.6)$ & $10(1.3)$ & I (3.8) & $15(2.1)$ & 0.338 \\
\hline LAMA + LABA & $14(8.3)$ & $60(8.1)$ & $2(7.7)$ & $52(7.4)$ & 0.959 \\
\hline ICS/LABA + LAMA & $18(10.7)$ & $170(22.9)$ & $14(53.8)$ & $342(48.6)$ & $<0.001$ \\
\hline ICS/LABA + LAMA + other & 0 & $3(0.4)$ & 0 & $10(1.4)$ & 0.089 \\
\hline Other & $5(3.0)$ & $38(5.1)$ & I (3.8) & $63(8.9)$ & 0.005 \\
\hline $\begin{array}{l}\text { Recommended by GOLD } 2014 \\
\text { as first/alternative choice }\end{array}$ & & $\begin{array}{l}\text { OLD } 2014 \text { as first } \\
\text { ative choice }\end{array}$ & & & \\
\hline
\end{tabular}

Note: aMaintenance regimens include \pm SABA, SAMA, or SABA/SAMA.

Abbreviations: GOLD, Global Initiative for Chronic Obstructive Lung Disease; ICS, inhaled corticosteroids; LABA, long-acting $\beta_{2}$-agonist; LAMA, long-acting muscarinic antagonist; SABA, short-acting $\beta_{2}$-agonist; SAMA, short-acting muscarinic antagonist. 
Significant differences were observed between the GOLD groups for short-acting only, long-acting $\beta_{2}$-agonist (LABA), long-acting muscarinic antagonist (LAMA), and triple-therapy regimens (Table 2).

Single-agent bronchodilator use was significantly more common in groups A and B $(P<0.05)$. Single-inhaler LAMA-only treatment represented the most frequently prescribed treatment in groups $\mathrm{A}$ and $\mathrm{B}(P<0.0001$ vs groups $\mathrm{C}$ and D). Inhaled corticosteroid (ICS) therapy, in dual or triple combination, was prescribed across all GOLD groups. In groups $\mathrm{C}$ and $\mathrm{D}, \mathrm{ICS} / \mathrm{LABA}+\mathrm{LAMA}$ triple-therapy regimen represented the most frequently prescribed therapy, despite not being recommended for group C patients by GOLD, and was prescribed for significantly higher proportions of patients than in groups $\mathrm{A}$ and $\mathrm{B}(P<0.0001)$. The proportion of patients being prescribed single-agent LAMA + LABA dual therapy (ie, LAMA and LABA in separate devices) was similar across all GOLD groups (range 7.4\%-8.3\%; not significant).

\section{Current treatment according to objective GOLD classification by primary care physician or pulmonologist}

Similar treatment patterns were observed for those patients receiving primary care physician or pulmonologist care (Figure 2), although a higher proportion of patients in group D (17.4\%) were prescribed single bronchodilator therapy by primary care physicians. This proportion was lower (8.9\%) for group D patients seeing a pulmonologist. In addition, a higher proportion of patients in group D seeing a pulmonologist were receiving triple therapy than those under the care of a primary care physician (Figure 2).

Both primary care physicians and pulmonologists prescribed ICS/LABA dual therapy for a notable proportion of patients in group A $(20.2 \%$ and $10.7 \%$, respectively) and group B (26.4\% and 16.3\%, respectively; Figure 2). Primary care physicians and pulmonologists also prescribed ICS/LABA + LAMA triple therapy to patients in group A (7.1\% and $14.3 \%$, respectively), group B (17.7\% and $27.1 \%$, respectively), and group $\mathrm{C}(50.0 \%$ and $57.1 \%$, respectively; Figure 2).

\section{Current treatment according to objective GOLD classification by length of patient diagnosis}

Analysis of current treatment by GOLD group for patients diagnosed within $\leq 12$ months or $>12$ months of the survey is shown in Figure 3. In group A, 78.3\% of patients who were diagnosed within $\leq 12$ months received a bronchodilator-only treatment compared with $63.6 \%$ for patients diagnosed $>12$ months. A higher proportion of patients with a diagnosis of $>12$ months were receiving ICS-containing therapy versus those with a diagnosis of $\leq 12$ months. In all GOLD groups, ICS/LABA + LAMA triple therapy was prescribed to a smaller proportion of patients diagnosed $\leq 12$ months versus $>12$ months (Figure 3 ). The proportions of singleagent LAMA + LABA dual therapy prescriptions were similar across all GOLD groups, and between recently diagnosed patients and those with a longer-term diagnosis ( $7.3 \%$ vs $8.6 \%$ overall).

\section{Treatment by COPD symptom burden}

Overall, the mean (standard deviation) CAT score was 20.4 (8.4), with most patients reporting CAT scores of $\geq 10$ (88.1\%), indicating a high level of symptoms according to CAT score. For patients with low symptom burden (CAT scores 0-9), the most commonly prescribed treatment was a LAMA (30.3\%), followed by a short-acting bronchodilator and then an ICS/LABA + LAMA (both 16.4\%) (Table 3). This pattern was broadly similar for patients with CAT scores of $10-19$, where $27.1 \%$ were prescribed a LAMA and $26.9 \%$ were prescribed an ICS/LABA + LAMA. For patients with CAT scores of 20-29 and 30-40, the most commonly prescribed treatment was an ICS/LABA + LAMA $(37.1 \%$ and $48.4 \%$, respectively), followed by an ICS/LABA ( $20.1 \%$ and $18.4 \%$, respectively). A lower proportion of patients with CAT scores of 0-9 (33.8\%) were treated with an ICS in combination with a bronchodilator compared to patients with a higher symptom burden $(48.1 \%, 60.5 \%$, and $74 \%$ for patients with CAT scores of 10-19, 20-29, and 30-40, respectively).

The proportion of patients defined as symptomatic (CAT score $\geq 10$ ) was $79.7 \%$ for patients receiving bronchodilators alone and increased to $87.5 \%$ for single-agent LAMA + LABA dual therapy, $\geq 90 \%$ for patients receiving ICS with bronchodilators (ICS/LABA, 90.0\%; ICS + LABA, 93.8\%; ICS + LAMA, 92.6\%), and $94.1 \%$ for patients receiving triple therapy.

Overall, COPD symptoms were reported to be completely controlled or well controlled for $\sim 50 \%$ of patients $(53.7 \%$ and $46.5 \%$, based on patient reports and physician reports, respectively). There was a general trend of fewer patients with completely controlled and well-controlled COPD seen with increasing CAT score (Table 3).

\section{Discussion}

This cross-sectional survey of patients with COPD consulting for routine care in Europe and the USA confirmed a high 
A

Short-acting only LABA LAMA ICS/LABA 血ICS + LABA 目 ICS + LAMA

$\square$ LAMA + LABA 目 ICS/LABA + LAMA 罪ICS/LABA + LAMA + other $\square$ Other

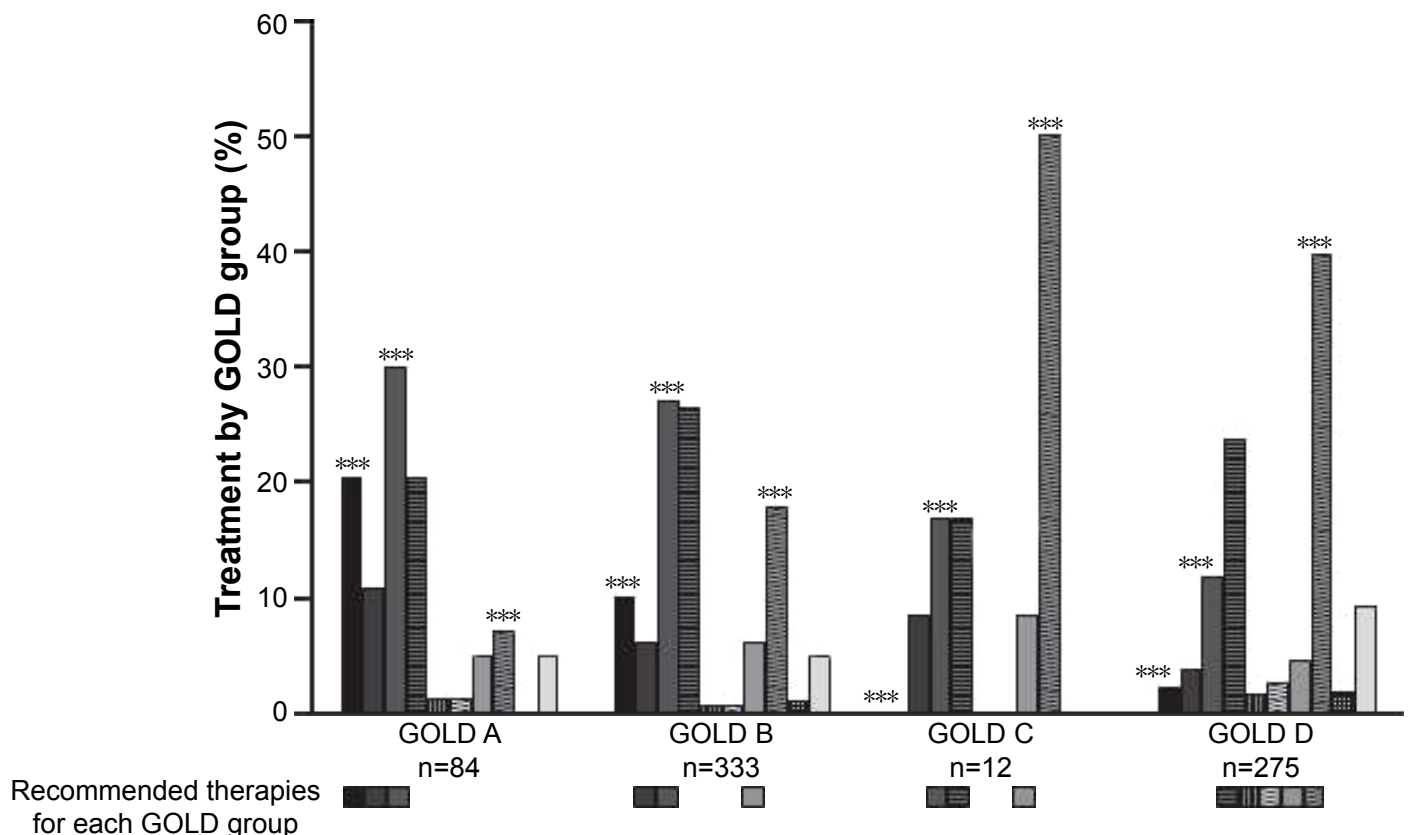

B

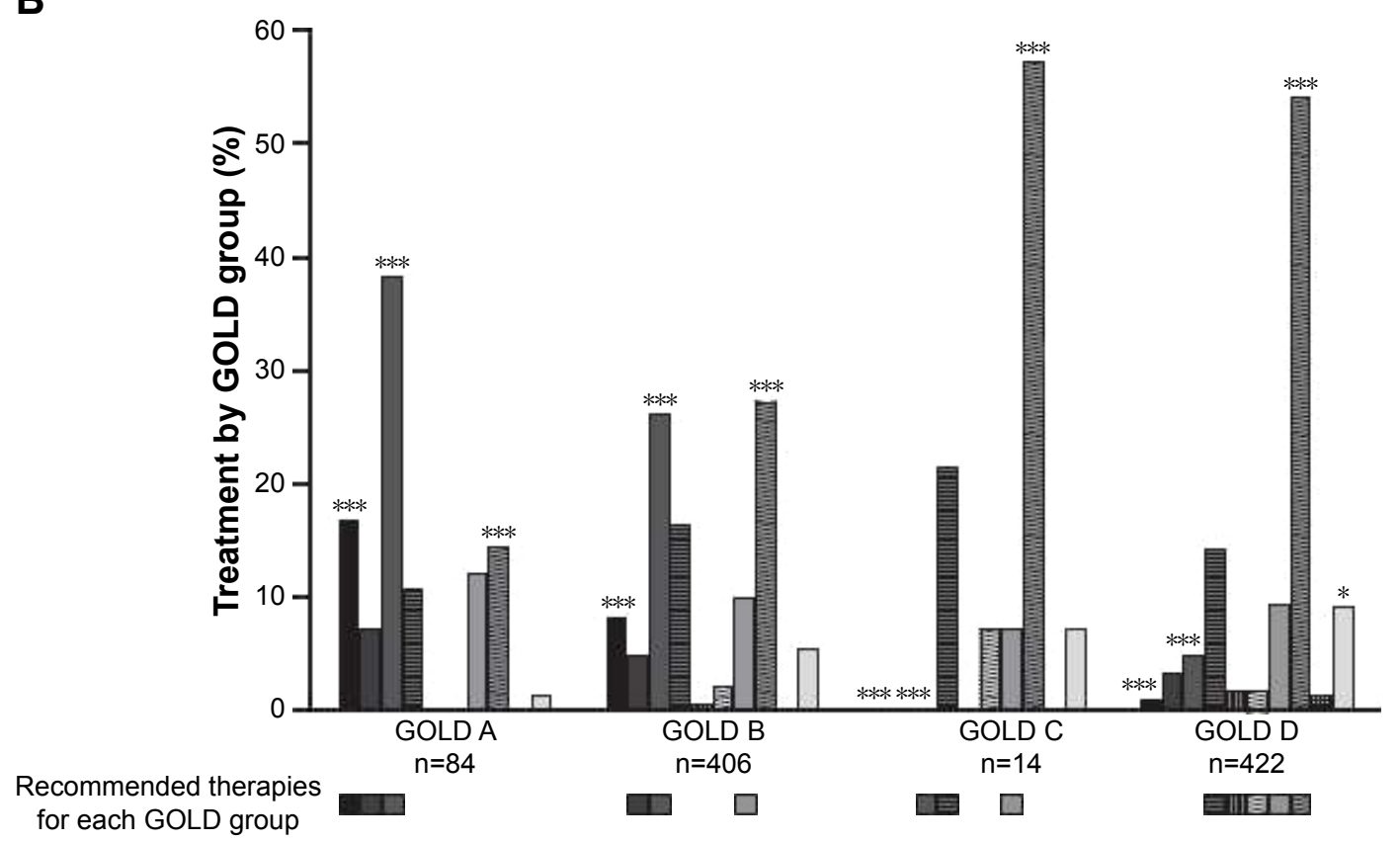

Figure 2 Current treatment according to objective GOLD classification for patients managed by (A) a primary care physician or (B) pulmonologist. ${ }^{2}$ Notes: $* P<0.05 ; * * * P<0.0001$ across GOLD groups A-D. aMaintenance regimens include \pm SABA, SAMA, or SABA/SAMA.

Abbreviations: GOLD, Global Initiative for Chronic Obstructive Lung Disease; ICSs, inhaled corticosteroids; LABA, long-acting $\beta_{2}$-agonist; LAMA, long-acting muscarinic antagonist; SABA, short-acting $\beta_{2}$-agonist; SAMA, short-acting muscarinic antagonist.

symptom burden despite treatment, evident from the high proportion of patients classified objectively as GOLD groups $\mathrm{B}$ and $\mathrm{D}$ and the high proportion of patients with CAT scores $\geq 10$.
The distribution of patients across the GOLD subgroups in this study contrasted with a recent retrospective database analysis of patients being prescribed a first maintenance therapy for COPD. In this study, patients were 


\section{A}

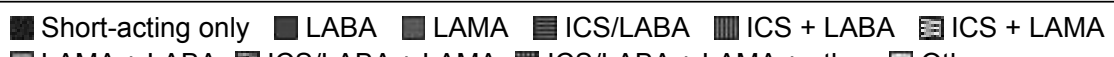

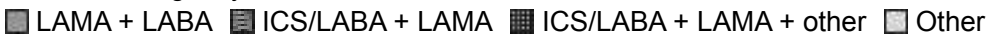

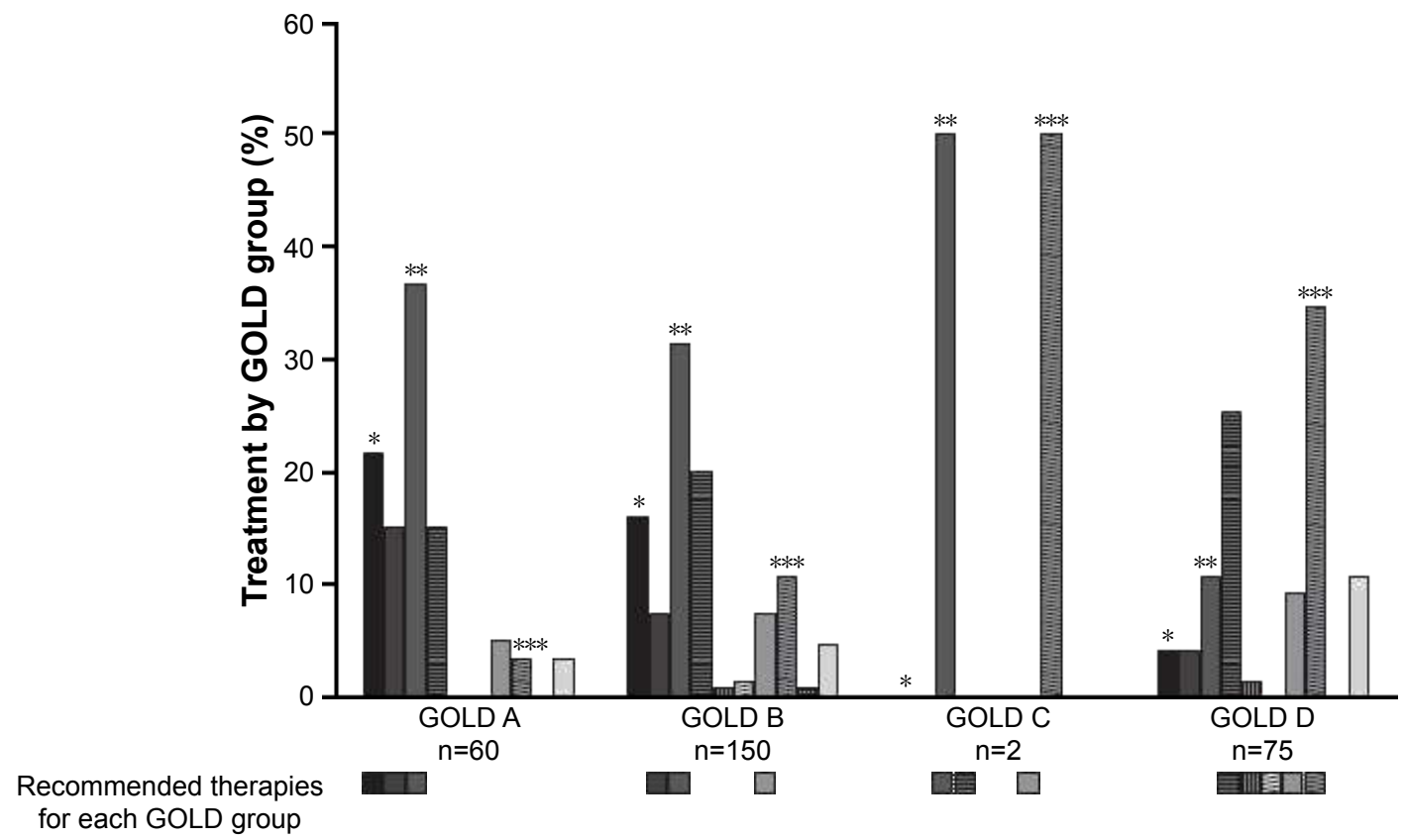

B

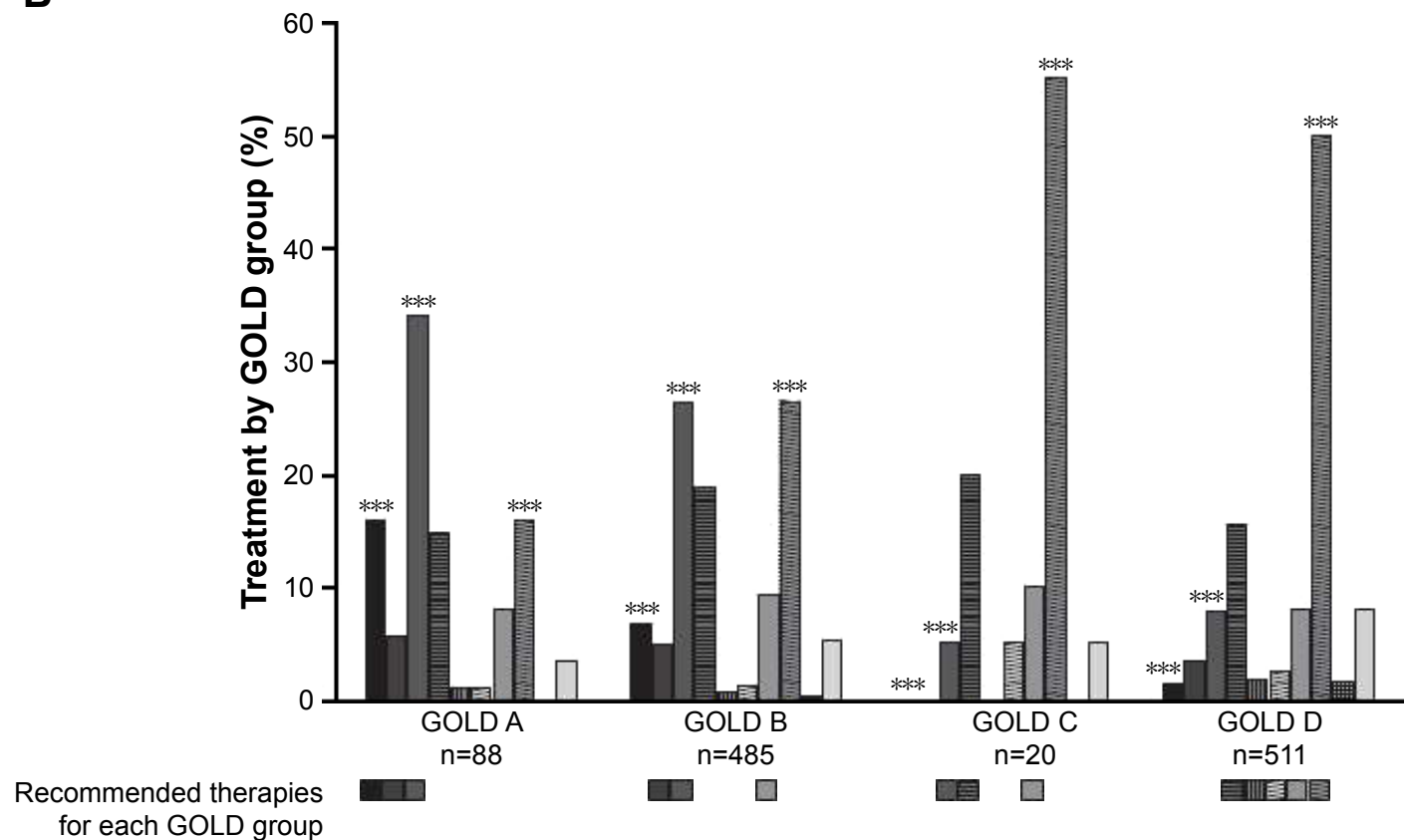

Figure 3 Current treatment according to objective GOLD classification for patients diagnosed $(\mathbf{A}) \leq 12$ months or $(\mathbf{B})>12$ months. ${ }^{a}$ Notes: $* P<0.05 ; * * P<0.01 ; * * * P<0.0001$ across GOLD groups A-D. aMaintenance regimens include \pm SABA, SAMA, or SABA/SAMA.

Abbreviations: GOLD, Global Initiative for Chronic Obstructive Lung Disease; ICS, inhaled corticosteroids; LABA, long-acting $\beta_{2}$-agonist; LAMA, long-acting muscarinic antagonist; SABA, short-acting $\beta_{2}$-agonist; SAMA, short-acting muscarinic antagonist.

more evenly distributed over the GOLD subgroups. ${ }^{19}$ In addition to the shorter disease duration compared to this study, these differences in patient distribution may be due to the method used to define the level of symptom burden, as the modified Medical Research Council (mMRC) score was used by Price et al, whereas this study used CAT score, which is a more comprehensive measure of symptoms. ${ }^{2,10}$ 
Table 3 Current treatment and proportion of patients with well-controlled symptoms by CAT

\begin{tabular}{|c|c|c|c|c|c|}
\hline \multirow[t]{3}{*}{ Patients, n (\%) } & \multicolumn{5}{|l|}{ CAT } \\
\hline & $0-9$ & $10-19$ & $20-29$ & $30-40$ & Overall \\
\hline & $n=195$ & $n=520$ & $n=676$ & $n=250$ & $n=|, 64|$ \\
\hline Short-acting only & $32(16.4)$ & $30(5.8)$ & $40(5.9)$ & $6(2.4)$ & $108(6.6)$ \\
\hline LABA & $16(8.2)$ & $27(5.2)$ & $30(4.4)$ & $6(2.4)$ & $79(4.8)$ \\
\hline LAMA & $59(30.3)$ & I4I (27.I) & $93(13.8)$ & $16(6.4)$ & $309(18.8)$ \\
\hline ICS/LABA & $31(15.9)$ & $97(18.7)$ & $136(20.1)$ & $46(18.4)$ & $310(18.9)$ \\
\hline ICS + LABA & I $(0.5)$ & $2(0.4)$ & $7(1.0)$ & $6(2.4)$ & $16(1.0)$ \\
\hline ICS + LAMA & $2(1.0)$ & $9(1.7)$ & $8(1.2)$ & $8(3.2)$ & $27(1.6)$ \\
\hline LAMA + LABA & $16(8.2)$ & $39(7.5)$ & $57(8.4)$ & $16(6.4)$ & $128(7.8)$ \\
\hline ICS/LABA + LAMA & $32(16.4)$ & $140(26.9)$ & $25 I(37.1)$ & $|2|(48.4)$ & $544(33.2)$ \\
\hline ICS/LABA + LAMA + other & 0 & $2(0.4)$ & $7(1.0)$ & $4(1.6)$ & $13(0.8)$ \\
\hline Other & $6(3.1)$ & $33(6.3)$ & $47(7.0)$ & $21(8.4)$ & $107(6.5)$ \\
\hline \multicolumn{6}{|c|}{ Patients with completely controlled or well-controlled COPD in past 4 weeks, $n$ (\%) } \\
\hline Physician reported & $157(80.5)$ & $359(69.0)$ & $321(47.5)$ & $45(18.0)$ & $882(53.7)$ \\
\hline Patient reported & $168(86.2)$ & $314(60.4)$ & $24 I(35.7)$ & $40(16.0)$ & $763(46.5)$ \\
\hline
\end{tabular}

Abbreviations: CAT, COPD assessment test; GOLD, Global Initiative for Chronic Obstructive Lung Disease; ICS, inhaled corticosteroid; LABA, long-acting $\beta_{2}$-agonist; LAMA, long-acting muscarinic antagonist.

Consistent with previous single-center or national real-world studies, ${ }^{12,13,19-22}$ data obtained in this study from over 900 physicians across Europe and the USA demonstrated a degree of misalignment between the GOLD recommendations and prescribing patterns. Based on objective classification of GOLD group, treatment of patients in the least (group A) and most severe (group D) subgroups was most likely to align with GOLD recommendations. However, treatment of patients in group B was less likely to align with GOLD recommendations, suggesting that these patients with a high symptom burden were not receiving optimal treatment. GOLD recommendations were overall more closely adhered to in recently diagnosed ( $<12$ months) patients and among those being treated by a pulmonologist.

The greatest use of single bronchodilator regimens (short- or long-acting) in group A patients was consistent with the GOLD report at the time of the study (2013), which recommended short-acting bronchodilators as the first choice of therapy for group A patients, with long-acting agents as an alternative choice. ${ }^{10}$ This was also reflected in the CAT score groups, where a larger proportion of patients with CAT scores of 0-9 were prescribed single bronchodilator treatment than in any other CAT score group. Patients in GOLD group D were most likely to receive a treatment that aligned with GOLD recommendations. ICS/LABA + LAMA triple therapy was consistently the most prescribed treatment to patients in group $\mathrm{D}$, particularly for patients being treated by a pulmonologist. However, ICS/LABA + LAMA triple therapy was also consistently the most prescribed treatment to patients in group $\mathrm{C}$, despite it not being recommended for this group of patients. ${ }^{10}$ This result must be interpreted with some caution, however, due to the small number of patients classified in this group. In terms of symptom burden, the prescribing of ICS in combination with bronchodilators was unsurprisingly higher in patients with CAT scores of $\geq 10$ than in patients with a low symptom burden (CAT scores 0-9).

Prescribing of single-agent LAMA + LABA dual therapy was similar and relatively low across all GOLD groups. This finding was surprising, as single-agent LAMA + LABA dual therapy was recommended by GOLD as an alternative choice of management regimen for patients in groups B-D. ${ }^{10,23,24}$ The observation that prescribing rates were slightly higher in patients diagnosed $>12$ months versus $\leq 12$ months might be explained by the fact that it was not recommended as a first choice. In GOLD group B, single-agent LAMA + LABA dual therapy prescribing rates were lower than those for several therapies that were not recommended by GOLD (short-acting bronchodilator only, ICS/LABA, and ICS/ LABA + LAMA).${ }^{10}$ Potential reasons for low single-agent LAMA + LABA dual therapy prescribing in group B may include cost and availability. However, there is some recent clinical evidence to suggest that LAMA/LABA fixed-dose combination therapies might benefit these patients if used as initial therapy instead of monotherapy. ${ }^{25}$

Use of ICS in combination with bronchodilators was prevalent (approximately 10\%-20\% of patients) among patients in GOLD groups A and B. This pattern was consistent with a previous analysis of the Respiratory $\mathrm{DSP}^{15}$ and was observed for patients treated by either a primary care physician or a pulmonologist. The benefit of ICS use in patients in GOLD groups A and B has been questioned due 
to the risk of adverse events ${ }^{26}$ and clinical evidence showing that some patients with COPD can benefit from bronchodilator therapy alone after steroid withdrawal. ${ }^{27,28}$

It is important to determine the risk-benefit rationale for the decision by physicians to prescribe ICS combinations for patients. A Taiwanese study of factors associated with the prescription of ICS in patients in GOLD groups A and $B$ found that wheezing was a significant predictor of ICS prescription in both groups, while a high CAT score was associated with ICS prescription in group B. ${ }^{29}$ Predictors of ICS/LABA prescribing included a diagnosis of asthma or previous exacerbation. ${ }^{30}$ Patients with a concomitant diagnosis of asthma were excluded from this study, so this was unlikely to contribute to the rates of ICS/LABA prescribing observed in patients in groups A and B; however, the realworld setting of the study cannot rule out some potential overlap between asthma and COPD. It was possible that an exacerbation in the previous year led to the decision to step up to an ICS-containing treatment. Alternatively, patients may have been prescribed an ICS due to exacerbations occurring $>12$ months ago and continued to use the ICS even though they were classified as GOLD group A or B during this study. However, a UK study showed that ICScontaining therapies were extensively prescribed to patients in GOLD groups A and B as a first COPD maintenance treatment option. ${ }^{19}$ In this study, the level of ICS prescribing among patients in groups A and B was greater in patients diagnosed $>12$ months ago versus those diagnosed in the previous 12 months. Therefore, these findings suggest that inappropriate ICS use began at first diagnosis and that the extent of ICS overprescribing may increase over time.

The reasons for the prevalent use of ICS-containing treatments across the GOLD groups were not addressed by this study, but may warrant further research, particularly since the most recent (2017) update to the GOLD report highlights a need for further studies of the long-term safety of ICS in patients with COPD. ${ }^{2}$ The prescribing of ICS for patients in GOLD groups $\mathrm{C}$ and $\mathrm{D}$ has been drawn into question due to the risk of pneumonia and because recent data suggested that a LAMA/LABA fixed-dose combination was superior to ICS/ LABA at preventing exacerbations. ${ }^{2,31,32}$ The updated GOLD report suggests that a LAMA/LABA fixed-dose combination is the recommended starting therapy for patients in group $\mathrm{D}$ and preferred to ICS/LABA for patients in group C. ${ }^{2}$ These recommendations are supported by the results of a recent meta-analysis, which compared treatment with LAMA + LABA versus ICS + LABA in patients with stable COPD and found that patients in the LAMA + LABA arm had a larger improvement of $\mathrm{FEV}_{1}$, fewer exacerbations, and a lower risk of pneumonia than patients treated with ICS + LABA. ${ }^{32}$

The latest iteration of the GOLD report contains noteworthy updates to the pharmacological treatment algorithms compared with the version in circulation at the time this survey was conducted. ${ }^{2,10}$ In particular, the updates now include ICS + LABA as an alternative choice for patients in GOLD groups $\mathrm{C}$ and $\mathrm{D}$ rather than the preferred treatment, which is now replaced by LAMA + LABA. Therefore, if the results of this study were considered in terms of the 2017 recommendations, the updated treatment paradigms would not markedly change the conclusion that there was misalignment between prescribing practices and the GOLD report. ${ }^{2,10}$ Notably, this survey was conducted before LAMA/LABA fixed-dose combinations were introduced, so it remains to be seen whether these relatively new treatment options and the updated GOLD guidelines influence the extent to which dual bronchodilators are prescribed for patients with COPD.

In addition to the updates to the pharmacological treatment guidelines in the 2017 GOLD report, the ABCD patient assessment system was also amended. At the time this analysis was performed, GOLD classified patients as high risk (GOLD group $\mathrm{C}$ or D) based on airflow limitation or exacerbation history, ${ }^{9,10}$ whereas patients are now classed as high risk based on exacerbation history only. ${ }^{2}$ If this recent assessment system had been in place in 2013 , 170 of the patients in this study would have been classified as group A, with 822, 23, and 613 in groups B, C, and D, respectively. The number of patients that would require reclassification was small, with three patients $(11.5 \%)$ in group C reclassified to group A and 91 patients (12.9\%) in group D reclassified to group B. Thirteen patients who were previously classified based on their $\mathrm{FEV}_{1}$ had missing exacerbation data so they could not be classified by using the new criteria. Hence, this small proportion of patients would not be expected to substantially alter the overall trend of the results of the study if the new method of patient classification was applied retrospectively.

\section{Limitations}

As the survey was cross-sectional, it was not possible to control for treatment effects (eg, patients currently classified as GOLD group B may have been classified in another group when the most recent prescribing decision was made). The cost and availability of the different classes of medications in the countries surveyed should also be considered in case any of the recommended treatments were unavailable. A further potential limitation was that this sample reflected 
patients visiting their doctor and, therefore, may not be generalizable to the overall population with COPD. Diagnosis of COPD was confirmed by the physician and, therefore, may have been dependent on their diagnostic skills; however, this is an accepted way of identifying a study sample in real-world research.

\section{Conclusion}

This study shows that patients with COPD present with a high symptom burden, regardless of exacerbation risk. In addition, there is a misalignment between GOLD recommendations and real-world treatment patterns for patients with COPD. In particular, use of ICS in combination with bronchodilators is prevalent among patients in GOLD groups A and B. Patients in GOLD group D were receiving treatments most aligned with those recommended by GOLD, while less than half of patients in GOLD group B were receiving recommended treatments, highlighting possible inappropriate treatment to address the symptoms of COPD.

\section{Acknowledgments}

The authors thank Gina Bergström of AstraZeneca, Gothenburg, Sweden, for her comments on an earlier version of the manuscript. The authors also thank Thomas Owens, $\mathrm{PhD}$, and Caroline Shepherd, BPharm of Complete Medical Communications, Macclesfield, UK, for providing medical writing support, which was funded by AstraZeneca, Cambridge, UK, in accordance with Good Publication Practice (GPP3) guidelines (Ann Intern Med 2015;163:461-464).

\section{Author contributions}

$\mathrm{BD}, \mathrm{MS}$, and UH contributed to conception and design of the study/analyses. MS was involved in data and statistical analyses and data acquisition. All authors contributed toward data analysis, drafting and revising the paper and agree to be accountable for all aspects of the work.

\section{Disclosure}

Ulf Holmgren and Bo Ding are employees of AstraZeneca. Mark Small is an employee of Adelphi Real World. The authors report no other conflicts of interest in this work.

\section{References}

1. Miravitlles M, Worth H, Soler Cataluna JJ, et al. Observational study to characterise 24-hour COPD symptoms and their relationship with patient-reported outcomes: results from the ASSESS study. Respir Res. 2014; $15: 122$.

2. Global Initiative for Chronic Obstructive Lung Disease. Global Strategy for the Diagnosis, Management and Prevention of COPD, Global Initiative for Chronic Obstructive Lung Diseases (GOLD) 2017 [updated 2017]. Available from: http://www.goldcopd.org. Accessed November 18, 2016.
3. Kessler R, Partridge MR, Miravitlles M, et al. Symptom variability in patients with severe COPD: a pan-European cross-sectional study. Eur Respir J. 2011;37(2):264-272.

4. Price D, Small M, Milligan G, Higgins V, Gil EG, Estruch J. Impact of night-time symptoms in COPD: a real-world study in five European countries. Int J Chron Obstruct Pulmon Dis. 2013;8:595-603.

5. Mullerova H, Lu C, Li H, Tabberer M. Prevalence and burden of breathlessness in patients with chronic obstructive pulmonary disease managed in primary care. PLoS One. 2014;9(1):e85540.

6. Ahmed T, Steward JA, O'Mahony MS. Dyspnoea and mortality in older people in the community: a 10-year follow-up. Age Ageing. 2012; 41(4):545-549.

7. Lange P, Marott JL, Vestbo J, Nordestgaard BG. Prevalence of nighttime dyspnoea in COPD and its implications for prognosis. Eur Respir J. 2014;43(6):1590-1598.

8. Roche N, Small M, Broomfield S, Higgins V, Pollard R. Real world COPD: association of morning symptoms with clinical and patient reported outcomes. COPD. 2013;10(6):679-686.

9. Global Initiative for Chronic Obstructive Lung Disease. Global Strategy for the Diagnosis, Management and Prevention of COPD, Global Initiative for Chronic Obstructive Lung Diseases (GOLD) 2016 [updated 2016]. Available from: http://www.goldcopd.org. Accessed October 30, 2016.

10. Global Initiative for Chronic Obstructive Lung Disease. Global Strategy for the Diagnosis, Management and Prevention of COPD, Global Initiative for Chronic Obstructive Lung Diseases (GOLD) 2014 [updated Jan 1, 2014]. Available from: http://www.goldcopd.org. Accessed October 30, 2016.

11. Jones P, Miravitlles M, van der MT, Kulich K. Beyond FEV(1) in COPD: a review of patient-reported outcomes and their measurement. Int J Chron Obstruct Pulmon Dis. 2012;7:697-709.

12. Franssen FM, Spruit MA, Wouters EF. Determinants of polypharmacy and compliance with GOLD guidelines in patients with chronic obstructive pulmonary disease. Int J Chron Obstruct Pulmon Dis. 2011; 6:493-501.

13. Price D, West D, Brusselle G, et al. Management of COPD in the UK primary-care setting: an analysis of real-life prescribing patterns. Int $J$ Chron Obstruct Pulmon Dis. 2014;9:889-904.

14. Koblizek V, Pecen L, Zatloukal J, et al. Real-life GOLD 2011 implementation: the management of COPD lacks correct classification and adequate treatment. PLoS One. 2014;9(11):e111078.

15. Vestbo J, Vogelmeier C, Small M, Higgins V. Understanding the GOLD 2011 Strategy as applied to a real-world COPD population. Respir Med. 2014;108(5):729-736.

16. White P, Thornton H, Pinnock H, Georgopoulou S, Booth HP. Overtreatment of COPD with inhaled corticosteroids-implications for safety and costs: cross-sectional observational study. PLoS One. 2013; 8(10): 75221 .

17. Anderson P, Benford M, Harris N, Karavali M, Piercy J. Real-world physician and patient behaviour across countries: disease-specific programmes-a means to understand. Curr Med Res Opin. 2008;24(11): 3063-3072.

18. Jones PW, Harding G, Berry P, Wiklund I, Chen WH, Kline Leidy N. Development and first validation of the COPD assessment test. Eur Respir J. 2009;34(3):648-654.

19. Price D, Miravitlles M, Pavord I, et al. First maintenance therapy for COPD in the UK between 2009 and 2012: a retrospective database analysis. NPJ Prim Care Respir Med. 2016;26:16061.

20. Brusselle G, Price D, Gruffydd-Jones K, et al. The inevitable drift to triple therapy in COPD: an analysis of prescribing pathways in the UK. Int J Chron Obstruct Pulmon Dis. 2015;10:2207-2217.

21. Seaman J, Leonard AC, Panos RJ. Health care utilization history, GOLD guidelines, and respiratory medication prescriptions in patients with COPD. Int J Chron Obstruct Pulmon Dis. 2010;5:89-97.

22. Corrado A, Rossi A. How far is real life from COPD therapy guidelines? An Italian observational study. Respir Med. 2012;106(7):989-997.

23. Appleton S, Poole P, Smith B, Veale A, Lasserson TJ, Chan MM. Long-acting beta2-agonists for poorly reversible chronic obstructive pulmonary disease. Cochrane Database Syst Rev. 2006;3:CD001104. 
24. Barr RG, Bourbeau J, Camargo CA, Ram FS. Inhaled tiotropium for stable chronic obstructive pulmonary disease. Cochrane Database Syst Rev. 2005;2:CD002876.

25. Donohue JF, Singh D, Munzu C, Kilbride S, Church A. Magnitude of umeclidinium/vilanterol lung function effect depends on monotherapy responses: results from two randomised controlled trials. Respir Med. 2016;112:65-74.

26. Nannini LJ, Lasserson TJ, Poole P. Combined corticosteroid and longacting beta(2)-agonist in one inhaler versus long-acting beta(2)-agonists for chronic obstructive pulmonary disease. Cochrane Database Syst Rev. 2012;9:CD006829.

27. Magnussen H, Disse B, Rodriguez-Roisin R, et al. Withdrawal of inhaled glucocorticoids and exacerbations of COPD. $N$ Engl J Med. 2014;371(14):1285-1294.

28. Nadeem NJ, Taylor SJ, Eldridge SM. Withdrawal of inhaled corticosteroids in individuals with COPD-a systematic review and comment on trial methodology. Respir Res. 2011;12:107.
29. Wei YF, Kuo PH, Tsai YH, et al. Factors associated with the prescription of inhaled corticosteroids in GOLD group A and B patients with C. Int J Chron Obstruct Pulmon Dis. 2015;10:1951-1956.

30. Drivenes E, Ostrem A, Melbye H. Predictors of ICS/LABA prescribing in COPD patients: a study from general practice. BMC Fam Pract. 2014; $15: 42$.

31. Wedzicha JA, Banerji D, Chapman KR, et al. Indacaterol-glycopyrronium versus salmeterol-fluticasone for COPD. N Engl J Med. 2016;374(23) 2222-2234.

32. Horita N, Goto A, Shibata Y, et al. Long-acting muscarinic antagonist (LAMA) plus long-acting beta-agonist (LABA) versus LABA plus inhaled corticosteroid (ICS) for stable chronic obstructive pulmonary disease (COPD). Cochrane Database Syst Rev. 2017;2:CD012066.
International Journal of COPD

\section{Publish your work in this journal}

The International Journal of COPD is an international, peer-reviewed journal of therapeutics and pharmacology focusing on concise rapid reporting of clinical studies and reviews in COPD. Special focus is given to the pathophysiological processes underlying the disease, intervention programs, patient focused education, and self management protocols.

\section{Dovepress}

This journal is indexed on PubMed Central, MedLine and CAS. The manuscript management system is completely online and includes a very quick and fair peer-review system, which is all easy to use. Visit http://www.dovepress.com/testimonials.php to read real quotes from published authors.

Submit your manuscript here: http://www.dovepress.com/international-journal-of-chronic-obstructive-pulmonary-disease-journal 